\title{
Pleural effusion in children associated with adenovirus infection
}

\author{
G Tiva, FC Paed; T Gray, Cert Paed Pulm; M Zampoli, Cert Paed Pulm; A Vanker, Cert Paed Pulm \\ Division of Paediatric Pulmonology, Department of Paediatrics and Child Health, Red Cross War Memorial Children's Hospital, \\ University of Cape Town, South Africa
}

Corresponding author: A Vanker (aneesa.vanker@uct.ac.za)

Viral pathogens are rare causes of pleural effusion in children. We present two cases of pleural effusions in children associated with adenovirus infection. Hepatomegaly with transaminitis, pleural fluid lymphocytosis and poor response to antibiotics were common features. Adenovirus infection should be considered in the differential diagnosis of pleural effusion in children.

S Afr Resp J 2015;21(3):78-79. DOI: 10.7196/10.2015.v21i3.78

Parapneumonic effusions constitute the majority of pleural effusions in children. ${ }^{[1]}$ Common aetiological pathogens include Streptococcus pneumoniae, Staphylococcus aureus and Mycobacterium tuberculosis (TB). ${ }^{[2]}$ The incidence of pneumococcal-related empyema is expected to decline since introduction of PCV13 in the South African immunisation programme in 2011. ${ }^{[3]} \mathrm{TB}$ and other pathogens, such as viruses, may therefore become relatively more important causes of pleural effusion in children. We report two cases of adenovirus-associated pneumonia and pleural effusion who presented with similar clinical features in which no other pathogen was identified.

\section{Case reports}

Case 1

A 16-month-old, previously well female was referred for pneumonia which was not improving despite 5 days of inpatient, broad-spectrum antibiotics. Perinatal history was uneventful and immunisations including PCV13 were up to date. She was febrile (temperature $38^{\circ} \mathrm{C}$ ), tachypnoeic (RR $64 \mathrm{bpm}$ ) and hypoxic with subcostal and intercostal recessions. There was stony dullness and reduced breath sounds over the right-lower zone, consistent with a large pleural effusion. She had a $4 \mathrm{~cm}$ hepatomegaly. Chest radiograph showed opacification of the right hemithorax (Fig. 1). A pleural effusion was confirmed by ultrasound and successfully drained by pigtail pleural catheter. Pleural fluid was sent for cytology, biochemical analysis, routine bacterial and mycobacterial culture, GeneXpert and respiratory virus polymerase chain reaction (PCR) (Anyplex ${ }^{\text {mix }}$ II RV16 Detection). Blood and microbiological investigations are presented in Table 1. Fever and symptoms persisted despite drainage and second-line antibiotics (ertapenem and clarithromycin). Anti-tuberculosis therapy was initiated but later withdrawn due to lack of evidence of TB disease. The patient showed gradual clinical and radiological improvement and the pleural drain was removed after 4 days. All bacterial cultures and TB investigations were negative. Adenovirus was isolated from the pleural fluid and induced sputum.

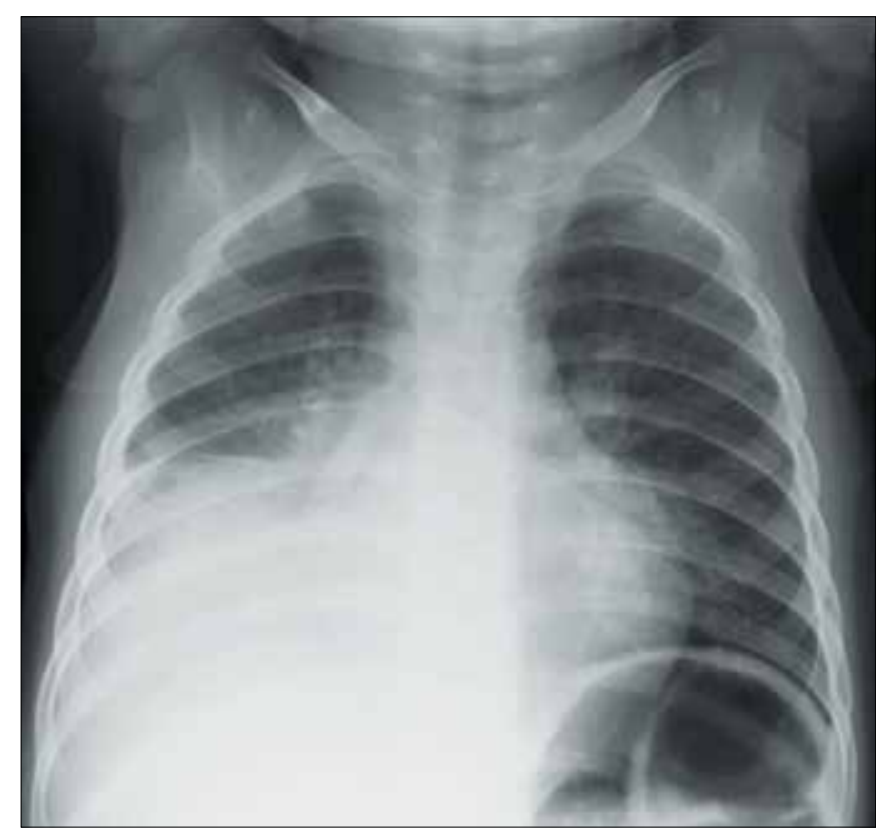

Fig. 1. Chest X-ray showing opacification of right lung and pleural effusion.

Case 2

A 10-month-old HIV-exposed but HIV-uninfected female was referred from a local clinic with pneumonia, acute gastroenteritis and severe dehydration. Immunisations, including PCV13, were up to date. On presentation she was febrile $\left(\mathrm{T} 38^{\circ} \mathrm{C}\right)$, severely dehydrated and shocked. She had signs of severe pneumonia: tachypnoea (RR $55 \mathrm{bpm}$ ), subcostal and intercostal recessions and hypoxia. Over 48 hours the gastroenteritis and dehydration resolved, but the fever and respiratory symptoms persisted despite broad antibiotic cover (cloxacillin and ceftriaxone). On day 2 admission the patient had a generalised seizure. Lumber puncture was done and was normal. Furthermore, stony dullness and decreased breath sounds over the right hemithorax suggested a pleural effusion, which was confirmed on a chest radiograph. A pigtail pleural drain was inserted and pleural 
Table 1. Routine blood and microbiological investigations.

\begin{tabular}{|c|c|c|}
\hline & Case 1 & Case 2 \\
\hline \multicolumn{3}{|l|}{ Bloods } \\
\hline HIV antibody test & Negative & Negative \\
\hline WCC $\left(\times 10^{6} / \mathrm{L}\right)$ & 13.66 & 10.99 \\
\hline CRP (mg/L) & 16.1 & 14.5 \\
\hline $\begin{array}{l}\text { Induced sputum (Gene Xpert } \\
\text { and TB culture) }\end{array}$ & Negative & Negative \\
\hline Mantoux & Negative & Test unavailable \\
\hline \multicolumn{3}{|l|}{ Liver enzymes } \\
\hline $\operatorname{ALP}(\mathrm{U} / \mathrm{L})(75$ - 316) & 238 & 241 \\
\hline GGT (U/L) (1 - 39) & 158 & 109 \\
\hline $\operatorname{ALT}(\mathrm{U} / \mathrm{L})(4-35)$ & 335 & 100 \\
\hline AST (U/L) $(0-65)$ & 986 & 132 \\
\hline LDH (U/L) (180 - 430) & 306 & 2888 \\
\hline \multicolumn{3}{|l|}{ Pleural fluid analysis } \\
\hline Protein (g/L) & 27 & 38 \\
\hline Glucose (mmol/L) & - & 7 \\
\hline LDH (U/L) & 763 & 5464 \\
\hline Polymorphs cells $/ \mathrm{mm}^{3}$ & 17 & 115 \\
\hline Lymphocytes cells $/ \mathrm{mm}^{3}$ & 560 & 1120 \\
\hline Erythrocytes cells $/ \mathrm{mm}^{3}$ & 480 & 880 \\
\hline Gene Xpert (PCR) & Negative & Negative \\
\hline Bacterial culture & Negative & Negative \\
\hline Viral panel PCR & Adenovirus & Adenovirus \\
\hline Blood culture & Negative & Negative \\
\hline Induced sputum viral PCR & Adenovirus & Adenovirus \\
\hline
\end{tabular}

fluid was sent for analysis. Blood and microbiological investigations are presented in Table 1. Anti-TB therapy was not initiated as there was no evidence of TB disease. The patient gradually improved and the pleural drain was removed after 7 days. All bacterial cultures and TB investigations were negative and adenovirus was isolated in the pleural fluid and induced sputum.

\section{Discussion}

We report two cases of adenoviral infection associated with pneumonia and unilateral pleural effusion. Parapneumonic effusions constitute the majority of paediatric pleural effusions, with bacterial infections being the most common. ${ }^{[1]}$ Viral infections are unusual causes of pleural effusion. They generally cause smaller effusions than those caused by bacterial infections and tend to resolve without intervention. A few cases of adenoviral effusions have been reported in the literature and occur mainly in epidemics. Serotype 3 and 7 have been implicated and present with a severe clinical course and raised transaminitis has been reported in some cases. ${ }^{[1,2]}$
Our two cases presented with acute systemic illness, pneumonia with unilateral pleural effusions and extra-pulmonary manifestations: hepatic inflammation in both cases and probable febrile convulsion in case 2. Despite empiric antibiotic cover, both patients showed little clinical improvement, which made a bacterial aetiology unlikely. Unremarkable infective markers and negative blood cultures supported this. However, the possibility of bacterial co-infection could not be excluded as antibiotic treatment was commenced prior to admission. Molecular methods such as PCR to identify bacterial pathogens may be useful in such cases. ${ }^{[4]}$

TB infection was considered the aetiology as both had pleural fluid lymphocytosis. However, the severe clinical course was not in keeping with TB. TB effusions present more indolently and are more common in older children and adults. ${ }^{[5]}$

Both cases had received three doses of pneumococcal conjugate vaccine (PCV13) as per the South African immunisation schedule. Since the introduction of PCV13 in the immunisation programme, incidences of pneumococcal-related pneumonia and pleural effusion are expected to decrease. ${ }^{[3]} \mathrm{TB}$ and other pathogens including viruses may become more prominent causes of paediatric pleural effusion.

Adenovirus was isolated from the pleural fluid and induced sputum of both cases, making adenovirus the most likely causative pathogen. Adenoviral serotyping was not done as it is not routinely available. Pleural fluid drainage and intensive supportive care management yielded a good outcome.

In conclusion, adenovirus infection should be considered in the differential diagnosis of pleural effusion in children, particularly those not responding to antimicrobial cover as expected.

Learning points

- Parapneumonic pleural effusions in children can be caused by viral infections.

- Pleural fluid analysis for respiratory viruses is a useful tool to confirm an underlying viral infection.

- Thoracentesis and supportive management yielded good results.

- Adenovirus infection should be considered in the differential diagnosis of pleural effusion in children, particularly those not responding to antimicrobial treatment.

\section{References}

1. Utine GE, Ozcelik U, Kiper N, et al. Pediatric pleural effusions: aetiological evaluation in 492 patients over 29 years. Turk J Pediatr 2009;51(3):214-219.

2. Honh JY, Lees HJ, Piedra PA, et al. Lower respiratory tract infections due to adenovirus in hospitalizated Korean children: Epidemiology, clinical features, and prognosis. Clin Infect Dis 2001;32(10):1423-1429. [http://dx.doi.org/10.1086/320146]

3. Simonsen L, Taylor RJ, Schuck-Paim C, Lustig R, Haber M, Klugman KP. Effect of 13-valent pneumococcal conjugate vaccine on admissions to hospital 2 years after its introduction in the USA: A time series analysis. Lancet Respir Med 2014;2(5):387394. [http://dx.doi.org/10.1016/S2213-2600(14)70032-3]

4. Blaschke AJ, Heyrend C, Byington CL, et al. Molecular analysis improves pathogen identification and epidemiologic study of pediatric parapneumonic empyema. Pediatr Infect Dis J 2011;30(4):289-294. [http://dx.doi.org/10.1097/INF.0b013e3182002d14]

5. Sharma S, Sarin R, Khalid UK, Singla N, Sharma PP, Behera D. Clinical profile and treatment outcome of tubercular pleurisy in pediatric age group using DOTS strategy. Indian J Tuberc 2009;56(4):191-200. 